\title{
Targeted next-generation sequencing of cancer-related genes in thyroid carcinoma: A single institution's experience
}

\author{
NOBUYUKI BANDOH ${ }^{1}$, TOSHIAKI AKAHANE ${ }^{2}$, TAKASHI GOTO ${ }^{1}$, MICHIHISA KONO ${ }^{1}$, HARUYUKI ICHIKAWA ${ }^{1}$, \\ TAKAHIRO SAWADA ${ }^{2}$, TOMOMI YAMAGUCHI ${ }^{2}$, HIROSHI NAKANO ${ }^{2}$, YUMIKO KAWASE ${ }^{2}$, YASUTAKA KATO ${ }^{2}$, \\ HAJIME KAMADA $^{2}$, YASUAKI HARABUCHI ${ }^{3}$, KAZUO SHIMIZU $^{4}$ and HIROSHI NISHIHARA ${ }^{2,5}$ \\ ${ }^{1}$ Department of Otolaryngology-Head and Neck Surgery; ${ }^{2}$ Department of Biology and Genetics, \\ Laboratory of Cancer Medical Science, Hokuto Hospital, Obihiro, Hokkaido 080-0833; \\ ${ }^{3}$ Department of Otolaryngology-Head and Neck Surgery, Asahikawa Medical University, Asahikawa, \\ Hokkaido 078-8510; ${ }^{4}$ Department of Endocrine Surgery, Kanaji Hospital, Tokyo 114-0015; \\ ${ }^{5}$ Keio Cancer Center, Keio University School of Medicine, Tokyo 160-8582, Japan
}

Received June 12, 2018; Accepted September 25, 2018

DOI: $10.3892 / \mathrm{ol} .2018 .9538$

\begin{abstract}
Thyroid carcinoma (TC) has characteristic genetic alterations, including point mutations in proto-oncogenes and chromosomal rearrangements that vary by histologic subtype. Recent developments in next-generation sequencing (NGS) technology enable simultaneous analysis of cancer-associated genes of interest, thus improving diagnostic accuracy and allowing precise personalized treatment for human cancer. A total of 50 patients who underwent thyroidectomy between 2014 and 2016 at Hokuto Hospital were enrolled. Total DNA was extracted from formalin-fixed, paraffin-embedded tissue sections and quantified. Targeted regions of 24 cancer-associated genes were amplified by PCR, barcoded and sequenced using an Illumina MiSeq platform. Subjects included 30 patients with papillary carcinoma (PC), two with PC tall cell variant (TVPC), two with PC follicular variant (FVPC), eight with follicular carcinoma, seven with poorly differentiated carcinoma (PDC), and one with anaplastic
\end{abstract}

Correspondence to: Dr Nobuyuki Bandoh, Department of Otolaryngology-Head and Neck Surgery, Hokuto Hospital, 7-5 Inadacho Kisen, Obihiro, Hokkaido 080-0833, Japan

E-mail: bando@hokuto7.or.jp

Abbreviations: TC, thyroid carcinoma; PC, papillary carcinoma; TVPC, papillary carcinoma tall cell variant; FVPC, papillary carcinoma follicular variant; FC, follicular carcinoma; PDC, poorly differentiated carcinoma; AC, anaplastic carcinoma; BRAF, v-raf murine sarcoma viral oncogene homolog B1; PI3K/Akt, phosphatidylinositol-3 kinase/v-Akt murine thymoma viral oncogene; PIK3CA, phosphatidylinositol-4, 5-bisphosphate 3-kinase catalytic subunit alpha isoform; EGFR, epidermal growth factor receptor; NGS, next-generation sequencing

Key words: thyroid carcinoma, papillary carcinoma, BRAF, PIK3CA, next-generation sequencing carcinoma (AC). The BRAF V600E mutation was present in 25 of $30(83 \%)$ patients with PC, 2 of $2(100 \%)$ patients with TVPC, 6 of 7 (86\%) patients of PDC, and one patient with AC. PIK3CA mutations were present in 3 of 30 (delPV104P, A1046T and C420R; 10\%) patients with PC and 1 of 7 (H1047R; 14\%) patients with PDC. The TP53 mutation was present in 1 of 30 (R306*; 3.3\%) patients with PC and 1 of 7 (Q152*; 14\%) patients with PDC. The NRAS mutation was present in 1 of $2(\mathrm{Q} 61 \mathrm{~K}, 50 \%)$ patients with FVPC. Statistical analysis showed that patients without the BRAF V600E mutation had advanced pathologic $\mathrm{T}$ and $\mathrm{N}$ stages compared with those with the mutation ( $\mathrm{P}=0.047$ and $\mathrm{P}=0.019$, respectively). The BRAF V600E mutation was not correlated with overall and disease-free survival in patients with $\mathrm{PC}$. A patient with PC with a mutation in EGFR (K852Q) and the PIK3CA mutation had an aggressive course with multiple bone and lung metastases. Detection of mutations in cancer-associated genes using NGS could enhance the understanding of the clinical behavior of TC.

\section{Introduction}

Thyroid carcinoma (TC) is the most common malignant tumor in endocrine organs, and its incidence has increased in recent decades (1). A major histologic subtype of TC is papillary carcinoma (PC), which has a good prognosis after surgical treatment. However, we rarely encounter PC patients with an aggressive clinical course such as bone or lung metastasis at the first clinic visit. Poorly differentiated thyroid carcinoma (PDC) represents an aggressive variant of TC with an incidence of 0.8 to $15 \%$, depending on the defining criteria and geographic location (2). Anaplastic carcinoma (AC) accounts for $<1 \%$ and has a median survival of 3 to 5 months (3). The initiation and progression of TC are associated with the accumulated genetic and epigenetic changes. The observed genetic changes frequently lead to activation of the MAPK or PI3K/Akt signaling pathways. Approximately $70 \%$ of TC cases demonstrated one of four 
genetic abnormalities: Point mutations in the $B R A F$ or $R A S$ genes or one of two chromosomal rearrangements (RET/PTC or $P A X 8 / P P A R \gamma)$ (4). PDC and $\mathrm{AC}$ are thought to arise from pre-existing $\mathrm{PC}$ or follicular carcinoma (FC) through additional genetic alterations, including CTNNB1 and TP53 mutations (5).

BRAF, a serine-threonine kinase and downstream signaling molecule of Ras and RET, is a potent activator of the MAPK signaling pathway $(1,6) . B R A F$ mutations have previously been reported in a broad range of human cancers, with the highest prevalence observed in melanoma and TC (6). A T1799A transversion mutation, which occurs in the kinase domain of $B R A F$, located on chromosome 7 , results in a single amino acid substitution of valine to glutamic acid (V600E). The $B R A F$ V600E mutation potently increases the kinase activity of BRAF by evoking a 480-fold increase in phosphorylation of ERK1/2 compared with wild-type BRAF, resulting in the expression of a number of genes that are involved in cell proliferation, differentiation, survival, tumorigenesis and promotion of epithelial-mesenchymal transition (7).

PIK3CA, the $\alpha$-type isoform of the catalytic subunit of phosphatidylinositol-3-kinase (PI3K), has been shown to harbor oncogenic mutations in human cancers (8). However, little is known about the role of PIK3CA gene mutations in patients with TC $(9,10)$. EGFR is a tyrosine kinase of the ErbB family that regulates signaling pathways for cellular proliferation and survival. Although many types of somatic mutations in the EGFR gene have been reported in non-small cell lung carcinoma (NSCLC), few reports have described such mutations in patients with TC (11).

Next-generation sequencing (NGS) technology enables the simultaneous analysis of hundreds of genes of interest using targeted sequence panels. NGS has been used in molecular tumor classification, and the prediction of recurrence and metastasis in some human cancers (12). NGS data are also useful in patient's management, facilitating risk stratification of patients based on the risk of malignancy. In the present report, we describe a patient with rare mutations and the results of mutational analysis using NGS. We attempted to correlate these mutations with clinicopathologic features of patients with TC.

\section{Patients and methods}

Patients. The study group consisted of 50 Japanese patients (45 females and 5 males) with a median age of 65 years (range, 26 to 86 years) who underwent curative surgery between 2012 and 2016 at Hokuto Hospital. Patients were classified according to the 8th edition of the AJCC/TNM staging system (13). Histological diagnosis was reviewed by the two experienced pathologists. PDC was diagnosed according to the Turin criteria (14). Written informed consent for publication of clinical details was obtained from all patients. Sampling, storage, and analysis of the tumor samples included in the present study were approved by the internal review board on ethical issues of Hokuto Hospital, Obihiro, Japan (Hokuto Hospital Institutional Ethics Committee no. 83).

Genetic analysis. Surgical specimens were obtained from 50 patients with TC who underwent thyroidectomy. Genetic analysis was performed according to the manufacturer's instructions $(15,16)$. Briefly, total DNA was extracted from $5-\mu \mathrm{m}$-thick formalin-fixed paraffin-embedded (FFPE) tissue sections of TC specimens and areas of no pathology using a Maxwell 16 FFPE Plus LEV DNA purification kit (Promega, Madison, WI). The quality of genomic DNA was assessed using a Qubit dsDNA BR assay kit (Life Technologies, Carlsbad, CA) and a GeneRead DNA QuantiMIZE assay kit (Qiagen, Valencia, CA). The GeneRead DNAseq Targeted Panels V2 Human Clinically Relevant Tumor Panel (NGHS-101X; Qiagen) was used for amplicon sequencing of targeted regions of 24 cancer-related genes ( $A K T 1, A L K, A R, B R A F, C T N N B 1$, DDR2, EGFR, ERBB2, FGFR3, GNA11, GNAQ, IDH1, IDH2, KIT, KRAS, MAP2K1, MET, NRAS, PDGFRA, PIK3CA, PTEN, RET, STK11, TP53). Library quality was assessed using an Agilent 2100 bioanalyzer (Agilent, Santa Clara, CA) and GeneRead Library Quant kit (Qiagen). The libraries were sequenced using an Illumina MiSeq (Illumina, San Diego, CA). Raw read data obtained from the amplicon sequencing were processed using online analytical resources from the GeneRead DNAseq Variant Calling Service for analysis of mutations.

Statistical analysis. The significance of differences between two groups was evaluated using Fisher's exact test and summarized with the appropriate P-value. A P-value $<0.05$ was considered indicative of statistical significance. Odds ratios and $95 \%$ confidence intervals were also calculated. Overall survival time was measured from the date of diagnosis to the date of death or date of last follow-up visit. Disease-free survival time was measured from the date of surgical removal of tumor to the date of first relapse or the date of last follow-up. The probability of overall and disease-free survival was calculated using the Kaplan-Meier method and compared using the log-rank test.

\section{Results}

Clinicopathologic features. Clinicopathologic features and mutational pattern in 50 patients with TC are listed in Table I. TC subtypes included $30(60 \%)$ patients with PC, $2(4 \%)$ with papillary carcinoma tall cell variant (TVPC), 2 (4\%) with papillary carcinoma follicular variant (FVPC), 8 (16\%) with FC, 7 (14) with PDC, and 1 (2\%) with AC. Tumor size ranged from 0.6 to $7.5 \mathrm{~cm}$ with a median size of $2.3 \mathrm{~cm}$. A total of 22 patients (44\%) were stage I, 17 (34\%) were stage II, $8(16 \%)$ were stage III, and $3(6 \%)$ were stage IVB. Hemi-thyroidectomy with routine central compartment and lateral neck lymph node dissection were performed in $29(58 \%)$ and $4(8 \%)$ patients, respectively. Total thyroidectomy with routine central compartment and lateral neck lymph node dissection were performed in $8(16 \%)$ and $9(18 \%)$ patients, respectively. Disease pathologic T classification of was T1a in $6(12 \%)$ patients, T1b in $4(8 \%)$, T2 in $7(14 \%)$, T3a in $3(6 \%)$, $\mathrm{T} 3 \mathrm{~b}$ in $16(32 \%)$, T4a in $13(26 \%)$ and $\mathrm{T} 4 \mathrm{~b}$ in $1(2 \%)$. The pathologic N classification was N0 in 24 (48\%) patients, N1a in 12 (24\%), and N1b in 14 (28\%). Pathologic extrathyroidal extension and multifocal tumors were observed in $30(60 \%)$ and $23(46 \%)$ patients, respectively. Follow-up period ranged from 8 to 78 months, with a median duration of 39 months for 
Table I. Clinicopathological features and mutational pattern in 50 patients with thyroid carcinoma.

\begin{tabular}{|c|c|c|c|c|c|c|c|c|c|c|c|c|}
\hline \multirow[b]{2}{*}{ No. } & \multirow[b]{2}{*}{ Age/sex } & \multirow[b]{2}{*}{ Histology } & \multirow{2}{*}{$\begin{array}{l}\text { Tumor } \\
\text { size, cm }\end{array}$} & \multirow[b]{2}{*}{ Stage } & \multicolumn{4}{|c|}{ Pathologic findings } & \multicolumn{4}{|c|}{ Mutation } \\
\hline & & & & & $\mathrm{pT}$ & $\mathrm{pN}$ & Extension & Multifocality & $B R A F$ & $P I K 3 C A$ & TP53 & Other \\
\hline 1 & $61 / \mathrm{F}$ & $\mathrm{PC}$ & 2.0 & I & $1 b$ & 0 & & + & V600E & & & \\
\hline 2 & $54 / \mathrm{F}$ & $\mathrm{PC}$ & 1.7 & $\mathrm{I}$ & $3 b$ & 0 & + & & V600E & & & \\
\hline 3 & $65 / \mathrm{F}$ & $\mathrm{PC}$ & 1.6 & $\mathrm{I}$ & $3 b$ & 0 & + & & V600E & & & \\
\hline 4 & $66 / \mathrm{F}$ & $\mathrm{PC}$ & 1.9 & I & $3 b$ & 0 & + & & V600E & & & \\
\hline 5 & $69 / \mathrm{F}$ & $\mathrm{PC}$ & 2.4 & $\mathrm{I}$ & $3 b$ & 0 & + & & V600E & & & \\
\hline 6 & $77 / \mathrm{F}$ & $\mathrm{PC}$ & 3.4 & $\mathrm{I}$ & 2 & 0 & & & V600E & & & \\
\hline 7 & $36 / \mathrm{F}$ & $\mathrm{PC}$ & 1.9 & $\mathrm{I}$ & $4 a$ & $1 \mathrm{a}$ & + & + & V600E & & & \\
\hline 8 & $75 / \mathrm{F}$ & $\mathrm{PC}$ & 2.5 & I & 2 & 0 & & + & V600E & & & \\
\hline 9 & $52 / \mathrm{M}$ & $\mathrm{PC}$ & 1.7 & I & $3 b$ & $1 \mathrm{a}$ & + & + & V600E & & & \\
\hline 10 & $54 / \mathrm{F}$ & $\mathrm{PC}$ & 0.8 & I & $1 \mathrm{a}$ & 0 & & + & V600E & & & \\
\hline 11 & $56 / \mathrm{F}$ & $\mathrm{PC}$ & 2.5 & II & $3 b$ & $1 \mathrm{a}$ & + & & V600E & & & \\
\hline 12 & $56 / \mathrm{M}$ & PC & 4.0 & II & 2 & $1 \mathrm{a}$ & & & V600E & & & \\
\hline 13 & $72 / \mathrm{F}$ & $\mathrm{PC}$ & 0.7 & II & $3 b$ & 0 & + & + & V600E & & & \\
\hline 14 & $67 / \mathrm{F}$ & $\mathrm{PC}$ & 2.3 & II & $3 b$ & $1 \mathrm{a}$ & + & & V600E & & & \\
\hline 15 & $63 / \mathrm{F}$ & $\mathrm{PC}$ & 3.1 & II & $3 b$ & $1 b$ & + & + & V600E & & & \\
\hline 16 & $71 / \mathrm{F}$ & $\mathrm{PC}$ & 5.0 & II & $3 b$ & $1 b$ & + & + & V600E & & & \\
\hline 17 & $62 / \mathrm{F}$ & $\mathrm{PC}$ & 2.2 & II & $3 b$ & $1 \mathrm{a}$ & + & & V600E & & & \\
\hline 18 & $55 / \mathrm{F}$ & $\mathrm{PC}$ & 1.6 & III & $4 a$ & $1 \mathrm{a}$ & + & & V600E & & & \\
\hline 19 & $73 / \mathrm{F}$ & $\mathrm{PC}$ & 2.3 & III & $4 a$ & $1 \mathrm{a}$ & + & & V600E & & & \\
\hline 20 & $73 / \mathrm{F}$ & $\mathrm{PC}$ & 2.3 & III & $4 a$ & 0 & + & + & V600E & & & \\
\hline 21 & $80 / \mathrm{F}$ & $\mathrm{PC}$ & 2.1 & III & $4 a$ & $1 b$ & + & & V600E & & & \\
\hline 22 & $56 / \mathrm{F}$ & $\mathrm{PC}$ & 1.4 & III & $4 a$ & $1 b$ & + & + & V600E & & & \\
\hline 23 & $86 / \mathrm{F}$ & $\mathrm{PC}$ & 1.1 & III & $4 a$ & 0 & + & & V600E & & & \\
\hline 24 & $77 / \mathrm{F}$ & $\mathrm{PC}$ & 2.7 & III & $4 a$ & 0 & + & & V600E & delPV104P & & \\
\hline 25 & $77 / \mathrm{F}$ & $\mathrm{PC}$ & 3.2 & II & $3 b$ & $1 b$ & + & + & V600E & A1046T & R306* & $\begin{array}{c}\text { FGFR3 } \\
\text { (G382R) }\end{array}$ \\
\hline 26 & $86 / \mathrm{F}$ & $\mathrm{PC}$ & 5.0 & IVB & $4 b$ & $1 b$ & + & + & & C420R & & $\begin{array}{c}E G F R \\
(\mathrm{~K} 852 \mathrm{Q})\end{array}$ \\
\hline 27 & $49 / \mathrm{F}$ & $\mathrm{PC}$ & 5.9 & I & $4 a$ & $1 b$ & + & & & & & \\
\hline 28 & $83 / \mathrm{F}$ & $\mathrm{PC}$ & 1.0 & III & $4 a$ & $1 b$ & + & & & & & \\
\hline 29 & $78 / \mathrm{F}$ & $\mathrm{PC}$ & 1.1 & II & $3 b$ & 0 & + & + & & & & \\
\hline 30 & $51 / \mathrm{M}$ & $\mathrm{PC}$ & 1.5 & I & $4 a$ & $1 b$ & + & + & & & & \\
\hline 31 & $26 / \mathrm{F}$ & TVPC & 0.8 & I & $3 b$ & $1 b$ & + & + & V600E & & & \\
\hline 32 & $83 / \mathrm{F}$ & TVPC & 4.5 & II & $3 b$ & $1 b$ & + & + & V600E & & & \\
\hline 33 & $85 / \mathrm{F}$ & FVPC & 4.4 & II & $3 a$ & 0 & & & & & & \\
\hline 34 & $56 / \mathrm{F}$ & FVPC & 1.7 & I & $1 b$ & 0 & & + & & & & $\begin{array}{c}N R A S \\
(\mathrm{Q} 61 \mathrm{~K})\end{array}$ \\
\hline 35 & $49 / \mathrm{F}$ & $\mathrm{FC}$ & 3.2 & I & 2 & 0 & & & & & & \\
\hline 36 & $76 / \mathrm{F}$ & $\mathrm{FC}$ & 3.6 & I & 2 & 0 & & & & & & \\
\hline 37 & $71 / \mathrm{F}$ & $\mathrm{FC}$ & 1.0 & I & $1 \mathrm{a}$ & 0 & & & & & & \\
\hline 38 & $56 / \mathrm{F}$ & $\mathrm{FC}$ & 3.4 & I & 2 & 0 & & & & & & \\
\hline 39 & $55 / \mathrm{F}$ & $\mathrm{FC}$ & 7.5 & I & $1 \mathrm{a}$ & 0 & & & & & & \\
\hline 40 & $54 / \mathrm{F}$ & $\mathrm{FC}$ & 3.6 & I & 2 & 0 & & & & & & \\
\hline 41 & $74 / \mathrm{F}$ & $\mathrm{FC}$ & 6.5 & II & $3 a$ & 0 & & & & & & \\
\hline 42 & $71 / \mathrm{M}$ & $\mathrm{FC}$ & 4.6 & II & $3 a$ & 0 & & & & & & \\
\hline 43 & $76 / \mathrm{F}$ & PDC & 1.6 & II & $1 b$ & $1 \mathrm{a}$ & & + & V600E & & & \\
\hline 44 & $81 / \mathrm{F}$ & PDC & 4.2 & IVB & $4 a$ & $1 b$ & + & + & V600E & & & \\
\hline 45 & $74 / \mathrm{F}$ & PDC & 1.4 & II & $1 b$ & $1 \mathrm{a}$ & & & V600E & & & \\
\hline 46 & $74 / \mathrm{F}$ & PDC & 2.0 & II & $3 b$ & 0 & + & & V600E & & & \\
\hline 47 & $51 / \mathrm{F}$ & PDC & 2.5 & I & $4 a$ & $1 \mathrm{a}$ & + & + & V600E & & & \\
\hline
\end{tabular}


Table I. Continued.

\begin{tabular}{|c|c|c|c|c|c|c|c|c|c|c|c|c|}
\hline \multirow[b]{2}{*}{ No. } & \multirow[b]{2}{*}{ Age/sex } & \multirow[b]{2}{*}{ Histology } & \multirow{2}{*}{$\begin{array}{c}\text { Tumor } \\
\text { size, cm }\end{array}$} & \multirow[b]{2}{*}{ Stage } & \multicolumn{4}{|c|}{ Pathologic findings } & \multicolumn{4}{|c|}{ Mutation } \\
\hline & & & & & pT & $\mathrm{pN}$ & Extension & Multifocality & $B R A F$ & PIK3CA & TP53 & Other \\
\hline 48 & 28/M & PDC & 1.0 & I & $1 \mathrm{a}$ & $1 \mathrm{~b}$ & & + & & V600E & H1047R & \\
\hline 49 & $67 / \mathrm{F}$ & PDC & 0.7 & II & $1 \mathrm{a}$ & $1 \mathrm{a}$ & & + & & & & \\
\hline 50 & $86 / \mathrm{F}$ & $\mathrm{AC}$ & 0.6 & IVB & $1 \mathrm{a}$ & $1 b$ & & + & & V600E & & Q192* \\
\hline
\end{tabular}

F, female; M, male; PC, papillary carcinoma; TVPC, papillary carcinoma tall cell variant; FVPC, papillary carcinoma follicular variant; FC, follicular carcinoma; PDC, poorly differentiated carcinoma; AC, anaplastic carcinoma; pT, pathological T stage; pN, pathological N stage.

all patients. Forty-five $(90 \%)$ of the patients are alive without disease. Three (6\%) patients (PC: 1 , PDC: 1 , and AC: 1$)$ died of disease due to distant metastasis. One patient with PC was alive with neck lymph node recurrence, and 1 patient with PC was alive with lung metastasis at the time of this report.

Mutational analysis. The BRAF V600E mutation was present in $25(83 \%)$ of 30 patients with PC, in $2(100 \%)$ of 2 with TVPC, in $6(86 \%)$ of 7 with PDC, and in $1 \mathrm{AC}$ patient (100\%). PIK3CA mutations were present in 3 (delPV104P, A1046T, and C420R; 10\%) of 30 patients with PC and 1 (H1047R; 14\%) of 7 with PDC. TP53 mutations were present in 1 (R306*; 3.3\%) of 30 patients with PC and 1 (Q152*; 14\%) of 7 with PDC. An NRAS mutation $(\mathrm{Q} 61 \mathrm{~K})$ was present in 1 of 2 patients with FVPC. An FGFR3 mutation (G382R) was present in 1 of 30 patients with PC, and an EGFR mutation (K852Q) was present in 1 of 30 patients with PC.

Correlation of BRAF V600E mutation with clinicopathologic factors in $P C$. Statistical analyses of the 30 patients with PC showed no significant correlation between the BRAF V600E mutation and clinicopathologic factors such as age, sex, tumor size, stage, extrathyroidal extension, and multifocal tumor (Table II). However, patients without the BRAF V600E mutation had more advanced pathologic $\mathrm{T}$ and $\mathrm{N}$ stages compared to patients with the mutation $(\mathrm{P}=0.047$ and $\mathrm{P}=0.019$, respectively). Kaplan-Meier analysis showed that $B R A F$ V600E mutation was not significantly correlated with overall $(\mathrm{P}=0.299$, Fig. $1 \mathrm{~A})$ or disease-free survival $(\mathrm{P}=0.401$, Fig. $1 \mathrm{~B})$ in patients with $\mathrm{PC}$.

Case presentation of patient no. 26. An 86-year-old female complained of dyspnea and suffered from pathologic fracture of the left femur. Enhanced computed tomography (CT) scan revealed a thyroid tumor with invasion of the trachea and esophagus (Fig. 2A). CT and fluorodeoxyglucose (FDG)-positron emission tomography (PET)/CT scans showed multiple bone metastases, including to the cranial bone (Fig. 2B), humerus, and femur (Fig. 2C), as well as multiple lung metastases (Fig. 2D). Histologic analysis of specimens from the thyroid tumor indicated PC. Genetic analysis of the thyroid tumor using NGS showed that the patient harbored EGFR (K852Q) and PIK3CA (C420R) mutations but no BRAF mutation. After total thyroidectomy with tracheal resection, the patient died, 34 months after the first clinic visit.

\section{Discussion}

$B R A F$ mutations in TC have been vigorously investigated since the early 2000s $(17,18)$. The frequency of the $B R A F$ V600E mutation reportedly ranges from 32 to $80 \%$ in patients with PC (4,19-21). Several large-scale multicenter studies reported that the average frequency of the $B R A F \mathrm{~V} 600 \mathrm{E}$ mutation in PC is approximately $48 \%(22,23)$. In the present study, the frequency of the BRAF V600E mutation in PC was $83 \%$, which was higher than that previously reported. The frequency in the present study may be biased due to the small number of patients analyzed. However, the higher frequency could also be attributed to tumors in patients from specific geographic locations and to methodologic differences. Recent studies from eastern Asia demonstrated a higher frequency of approximately $80 \%$ for the $B R A F$ V600E mutation in PC, which is consistent with our results (24-27). Residents in eastern Asia commonly consume seaweeds as a part of their regular diet. The region where our hospital is located, and in which all the patients involved in this study resided is well known for seaweed production and consumption. Iodine intake has been linked with a higher frequency of $B R A F$ mutations in Korean patients with PC (28). Guan et al (29) reported that high iodine intake is associated with a higher prevalence of the $B R A F$ V600E mutation in Chinese patients with PC. Elisei et al (30) suggested that iodine supplementation might be associated with the increasing trend of $B R A F$ mutation in PC.

The frequency of $B R A F$ mutations reported in the literature has increased significantly over the years (31). This may be related to innovations in methodologies used to detect mutations. The use of NGS could be associated with the higher frequency of the $B R A F \mathrm{~V} 600 \mathrm{E}$ mutation in patients with PC noted in the present study. To date, the frequency of the $B R A F$ V600E mutation in patients with PC has been analyzed using Sanger sequencing (SGS) with FFPE $(21,26)$, SGS with frozen tissue (32,33), pyrosequencing (34) and real-time PCR (27). In the present study, we analyzed FFPE tissue sections obtained from 50 patients with TC using an Illumina Miseq sequencer. Since 2013, only 2 reports concerning PC and 2 reports concerning PDC and AC were published describing results of mutational analyses using NGS with FFPE tissue sections (2,35-37). Tumor samples are histologically heterogeneous (15), and tumor-specific DNA contains varying proportions of contaminating DNA from normal and inflammatory cells. NGS methods enables the analysis of somatic 
Table II. Correlation of BRAF V600E mutation with clinicopathologic factors in 30 patients with papillary carcinoma.

\begin{tabular}{|c|c|c|c|c|c|c|}
\hline \multirow[b]{2}{*}{ Variables } & \multirow[b]{2}{*}{ No. of patients } & \multicolumn{2}{|c|}{$\begin{array}{c}B R A F \\
\text { V600E mutation }\end{array}$} & \multirow[b]{2}{*}{ P-value } & \multirow[b]{2}{*}{ OR } & \multirow[b]{2}{*}{$95 \% \mathrm{CI}$} \\
\hline & & $+(\mathrm{n}=25)$ & $-(\mathrm{n}=5)$ & & & \\
\hline \multicolumn{7}{|c|}{ Age, years } \\
\hline$<55$ & 6 & 4 & 2 & \multirow[t]{2}{*}{0.254} & 1.00 & \\
\hline$\geq 55$ & 24 & 21 & 3 & & 0.29 & $0.04-2.30$ \\
\hline \multicolumn{7}{|l|}{ Sex } \\
\hline Male & 3 & 2 & 1 & \multirow[t]{2}{*}{0.434} & 1.00 & \\
\hline Female & 27 & 23 & 4 & & 0.35 & $0.02-4.80$ \\
\hline \multicolumn{7}{|c|}{ Tumor size, cm } \\
\hline$<2$ & 14 & 11 & 3 & \multirow[t]{2}{*}{0.642} & 1.00 & \\
\hline$\geq 2$ & 16 & 14 & 2 & & 0.52 & $0.07-3.70$ \\
\hline \multicolumn{7}{|l|}{ Stage } \\
\hline I, II & 21 & 18 & 3 & \multirow[t]{2}{*}{0.622} & 1.00 & \\
\hline III, IVB & 9 & 7 & 2 & & 1.71 & $0.23-12.60$ \\
\hline \multicolumn{7}{|l|}{ pT } \\
\hline $1 a-3 b$ & 19 & 18 & 1 & \multirow[t]{2}{*}{0.047} & 1.00 & \\
\hline $4 a, 4 b$ & 11 & 7 & 4 & & 10.29 & $1.00-109.00$ \\
\hline \multicolumn{7}{|l|}{$\mathrm{pN}$} \\
\hline $0,1 \mathrm{a}$ & 21 & 20 & 1 & \multirow[t]{2}{*}{0.019} & 1.00 & \\
\hline $1 \mathrm{~b}$ & 9 & 5 & 4 & & 16.00 & $1.45-177.00$ \\
\hline \multicolumn{7}{|c|}{ Extrathyroidal extension } \\
\hline- & 5 & 5 & 0 & \multirow[t]{2}{*}{0.556} & 1.00 & \\
\hline+ & 25 & 20 & 5 & & 1.25 & $1.02-1.52$ \\
\hline \multicolumn{7}{|c|}{ Multifocality } \\
\hline- & 16 & 14 & 2 & \multirow[t]{2}{*}{0.642} & 1.00 & \\
\hline+ & 14 & 11 & 3 & & 1.91 & $0.27-13.50$ \\
\hline
\end{tabular}

P-values were calculated with Fisher's exact test. OR, odds ratio; CI, confidence interval; pT, pathological T stage; pN, pathological N stage.

mutation using a small amount of tumor-specific DNA (38). NGS can detect a broad range of mutations, including single nucleotide substitutions, small insertions and deletions, and large genomic duplications. Moreover, targeted NGS is more cost efficient and faster than SGS (39). In general, the detection sensitivity of NGS reported in previous studies is $>94 \%$ (40), which is greater than that of SGS.

Results from numerous studies and meta-analyses have associated the $B R A F$ V600E mutation with high-risk clinicopathologic features, such as larger tumor size, extrathyroidal extension, higher stage at presentation, and lymph node and distant metastases in patients with PC (4,20,22,30,31,41-43). However, these associations remain controversial. A number of other reports have suggested that there is no significant association between the BRAF V600E mutation and high-risk clinicopathologic features in patients with PC (25,34,44-46). In the present study, contrary results were obtained, in that PC patients without the BRAF V600E mutation had more advanced pathologic $\mathrm{T}$ and $\mathrm{N}$ stages compared to patients with the mutation. There have been few reports that support our results. The much lower number of patients without the $B R A F$
V600E mutation $(n=5)$ in our study compared with the number of patients with the mutation $(n=25)$ could have affected our results; that is, the $B R A F \mathrm{~V} 600 \mathrm{E}$ mutation-negative group could have been biased. However, 1 of the 5 PC patients without the BRAF V600E mutation was previously described in the case presentation as having PIK3CA and EGFR mutations. Three other patients without the BRAF V600E mutation had copy number alterations (CNAs) in either the PIK3CA, PTEN, $D D R 2, S T K 11$, or ERBB2 genes whereas only 2 of 25 patients with $B R A F$ V600E mutation had the alterations. We hypothesize that the accumulation of other genetic alterations except for the $B R A F$ V600E mutation might have contributed to the advanced pathologic stages in these patients.

A recent retrospective analysis of $1849 \mathrm{PC}$ patients found a mortality rate of $5.3 \%$ in $B R A F$ V600E mutation-positive patients vs. $1.1 \%$ in mutation-negative patients (43). In contrast, Pelttari et al (47) suggested that there was no association between the $B R A F \mathrm{~V} 600 \mathrm{E}$ mutation and recurrence following primary treatment with total thyroidectomy and radioiodine remnant ablation in patients with PC. A study of non-high-risk PC patients in Japan found no prognostic impact of the BRAF V600E 

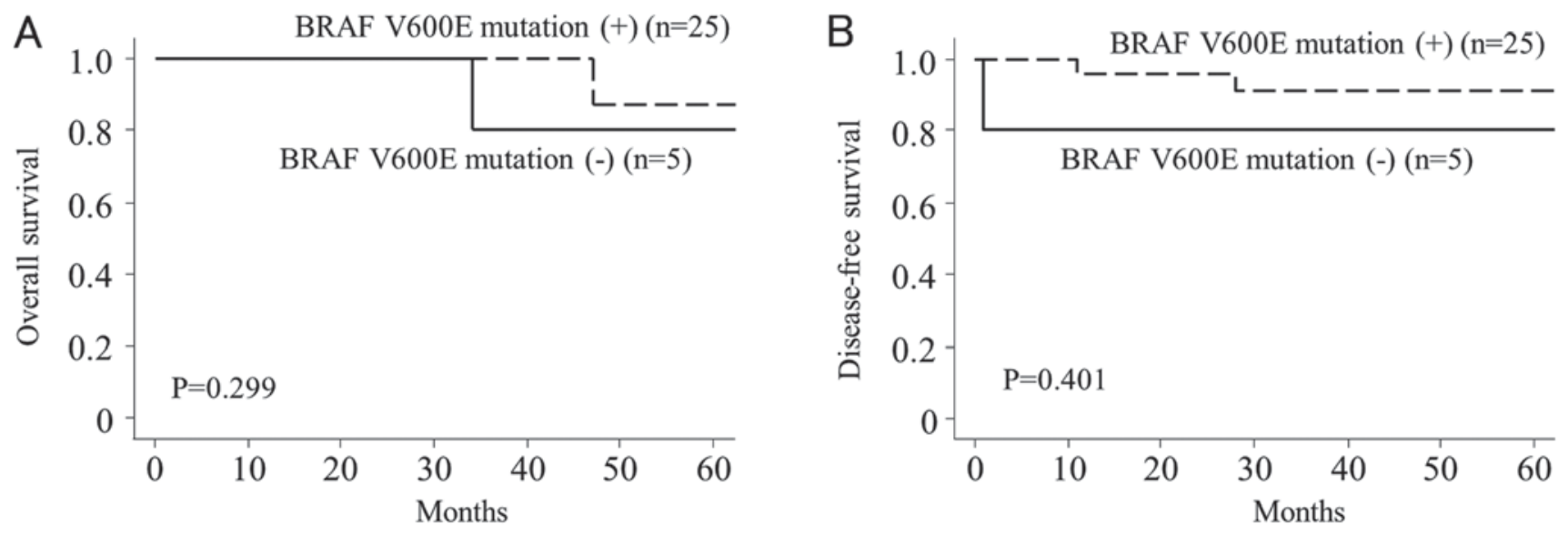

Figure 1. Kaplan-Meier survival curves for papillary carcinoma patients with $B R A F$ V600E mutation. There were no statistically significant differences in overall (A) or disease-free (B) survival between patients with and without the BRAF V600E mutation.
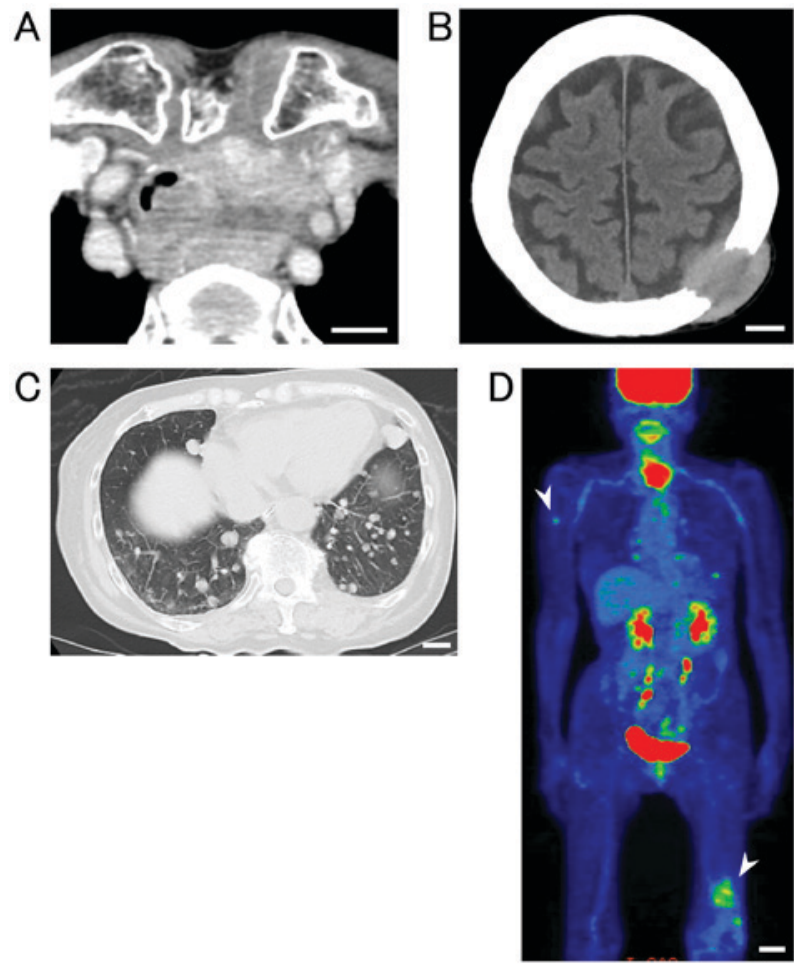

Figure 2. Imaging findings for patient no. 26 with $E G F R(\mathrm{~K} 852 \mathrm{Q})$ and PIK3CA (C420R) mutations but without the BRAF V600E mutation. (A) Enhanced neck CT scan revealed invasion of the thyroid tumor into the trachea and esophagus. CT scan indicated metastasis of tumors to the cranial bone (B) and the lung (C). Scale bar, $2 \mathrm{~cm}$. (D) FDG-PET/CT scan indicated metastasis of tumors to the right humerus and left femur (arrow heads). Scale bar, $5 \mathrm{~cm}$.

mutation on lymph node recurrence-free, distant recurrence-free, or cause-specific survival (46). In the present study, there was no correlation between the BRAF V600E mutation and overall and disease-free survival in patients with PC. We obtained inconsistent results, in that $\mathrm{PC}$ patients without the $B R A F \mathrm{~V} 600 \mathrm{E}$ mutation had more advanced pathologic $\mathrm{T}$ and $\mathrm{N}$ stages but did not show poor survival. That appropriate surgery was performed depending on the extention of $\mathrm{T}$ and $\mathrm{N}$ stages in these subjects could explain this inconsistency. Otherwise, other markers except for $B R A F$ V600E mutation may be associated with poorer prognosis. Shimamura et al (48) suggested that the BRAF V600E mutation alone is not sufficient for development of PC. This, however, does not mean that $B R A F \mathrm{~V} 600 \mathrm{E}$ is not the driver mutation, but rather that additional genetic and/or epigenetic changes may be required for full transformation in PC. Several other studies have agreed with this hypothesis, reporting associations between development of PC and increased expression of several tumor promoting molecules, including vimentin (49), matrix metalloproteinase (50), nuclear factor- $\kappa \mathrm{B}(51)$, prohibitin (52), vascular endothelial growth factor (53), and hepatocyte growth factor receptor (54). A recent report indicated that the telomerase reverse transcriptase (TERT) promoter is a poor prognostic factor in patients with $\mathrm{PC}(55)$.

In the present study, 2 patients with TVPC harbored the $B R A F$ V600E mutation, whereas 2 patients with FVPC and 8 patients with FC did not harbor the $B R A F$ V600E mutation. TVPC, a subtype of PC, is characterized by a predominance of tall and oncocytic tumor cells. Patients with TVPC exhibit a higher recurrence rate and decreased disease-specific survival (56). The $B R A F \mathrm{~V} 600 \mathrm{E}$ mutation is reportedly common in approximately $80 \%$ of TVPC cases (4). By contrast, in FVPC, another subtype of $\mathrm{PC}$, the BRAF V600E mutation is less common, reportedly found in only approximately $10 \%$ of patients $(4,57)$. FVPC is instead characterized by a high prevalence of mutations other than $B R A F$ V600E, such as mutations in $R A S$ and other factors, which has been associated with follicular-pattern thyroid tumors, including FC and follicular adenoma (4). The BRAF V600E mutation also occurs in PDC and $\mathrm{AC}$ arising from PC $(4,18)$. In the present study, 7 PDCs and 1 AC were pathologically diagnosed as derived from PC.

Mutations in PIK3CA that enhance PI3K/Akt signaling are associated with tumor progression and dedifferentiation in some human cancers and occur at an early stage in tumorigenesis in TC (9). Using an NGS approach, Nikiforova et al (35) showed that BRAF mutations are the most frequent (59\%), followed by mutation in PIK3CA (11\%), TP53 (7\%), and NRAS (4\%). Lee et al (26) also demonstrated $B R A F$ mutations in $79.2 \%$ of PC patients and PIK3CA mutations in $10.4 \%$. These data are consistent with our results demonstrating that the second most frequent genetic mutations occurred in PIK3CA 
in $10 \%$ of patients with PC. Over $90 \%$ of the mutations in the $P I K 3 C A$ gene in human cancers occur in 4 regions: The p85 binding (exons 1 and 2), C2 (exon 7), helical (exon 9), and catalytic (exon 20) domains (58). Four mutations in PIK3CA we identified were located within these regions, as previously reported. PIK3CA mutations are related to tumor development, progression and more aggressive behavior in TC (9). Therefore, detecting PIK3CA mutations in patients with $\mathrm{PC}$ is also critical (59).

In the case presentation, we presented a patient with EGFR and PIK3CA mutations who exhibited an aggressive clinical course. EGFR mutations are commonly found in NSCLC, but they are less common in PC. The most common genetic alterations in the EGFR gene are in-frame deletions in exon 19 and point mutations in exon 21 in the intracellular tyrosine kinase domain $(60,61)$. The role of EGFR mutation in TC remains unclear. Masago et al (11) reported 8PC patients with in-frame deletion and/or L858R mutations in EGFR. One of the 8 patients showed distant metastasis as the initial manifestation. A study of Korean patients found EGFR mutations and increased copy number in 14 of 23 analyzed samples, suggesting that $E G F R$ genetic alterations are correlated with the biological dedifferentiation process in TC (62). Of the 30 patients with PC in the present study, the patient who showed multiple bone and lung metastases at the first clinical visit and died with the disease had an EGFR mutation. We hypothesize that EGFR mutations in patients with PC are related to aggressive tumor behaviors such as multiple lung and bone metastases.

There are some limitations to the present study. First, we analyzed only 50 patients with TC, which was an insufficient number of patients to correlate mutational status with clinical significance. Most studies conducted to date were carried out at a single institution using specific subtypes of TC with small sample sizes. To overcome this limitation, multicenter studies examining TC by geographic location will be required. Second, we used a commercially available panel that targets only 24 cancer-related genes in the NGS analysis. The panel was not specific for TC and not able to elucidate the underlying mechanism of tumorigenesis in TC. Nikiforova et al has already conducted an analysis of gene fusions, CNA, and abnormal gene expression as well as mutational analysis of more than 100 genes with the latest panel ThyroSeq v3 for thyroid tumor (63). In this way, a thyroid cancer-specific gene panel that targets a larger number of cancer genes should be employed in conjunction with NGS. Furthermore, analysis of rearrangements in RET/PTC and PAX8/PPAR $\gamma$ in TC should be carried out. Comprehensive molecular testing of both gene mutations and rearrangements using new sequencing technologies will contribute to the development of new screening systems for predicting clinical outcome and assist in the development of new molecular target treatments.

In conclusion, NGS analysis of 24 cancer-related genes using FFPE tissue sections from 50 patients with TC revealed the $B R A F$ V600E mutation in $83 \%$ of patients with PC and $86 \%$ of patients with PDC. Statistical analyses showed that patients without this $B R A F$ mutation had more advanced pathologic $\mathrm{T}$ and $\mathrm{N}$ stages. A PC patient with EGFR and PIK3CA mutations but without the BRAF V600E mutation showed an aggressive course including multiple bone and lung metastases. Analysis of cancer-related genes using NGS approaches can enhance our understanding of the biological behavior of TC.

\section{Acknowledgements}

Not applicable.

\section{Funding}

No funding was received.

\section{Availability of data and materials}

All data generated or analyzed during this study are included in this published article.

\section{Authors' contributions}

NB, TG, MK, HI and KS performed surgery and acquired data. TA, TS and TY performed the mutational analyses. $\mathrm{HNa}$ and YuK confirmed the mutational analysis data. HNi and YaK performed the pathologic diagnoses. $\mathrm{HK}$ and $\mathrm{YH}$ conceived the study design. NB drafted the manuscript and analyzed the clinical data. All authors read and approved the final version of the manuscript.

\section{Ethics approval and consent to participate}

Written informed consent for publication of clinical details was obtained from all patients. Sampling, storage, and analysis of the tumor samples included in the present study were approved by the internal review board on ethical issues of Hokuto Hospital, Obihiro, Japan (Hokuto Hospital Institutional Ethics Committee no. 83).

\section{Patient consent for publication}

Not applicable.

\section{Competing interests}

The authors declare that they have no competing interests.

\section{References}

1. Xing M: BRAF mutation in papillary thyroid cancer: Pathogenic role, molecular bases, and clinical implications. Endocr Rev 28: 742-762, 2007.

2. Gerber TS, Schad A, Hartmann N, Springer E, Zechner U and Musholt TJ: Targeted next-generation sequencing of cancer genes in poorly differentiated thyroid cancer. Endocr Connect 7: 47-55, 2018.

3. Jeon MJ, Chun SM, Kim D, Kwon H, Jang EK, Kim TY, Kim WB, Shong YK, Jang SJ, Song DE and Kim WG: Genomic alterations of anaplastic thyroid carcinoma detected by targeted massive parallel sequencing in a BRAF (V600E) mutation-prevalent area. Thyroid 26: 683-690, 2016.

4. Nikiforov YE: Molecular analysis of thyroid tumors. Mod Pathol 24 (Suppl 2): S34-S43, 2011.

5. Kondo T, Ezzat S and Asa SL: Pathogenetic mechanisms in thyroid follicular-cell neoplasia. Nat Rev Cancer 6: 292-306, 2006.

6. Davies H, Bignell GR, Cox C, Stephens P, Edkins S, Clegg S, Teague J, Woffendin $\mathrm{H}$, Garnett MJ, Bottomley W, et al: Mutations of the BRAF gene in human cancer. Nature 417: 949-954, 2002 
7. Vasko V, Espinosa AV, Scouten W,He H, Auer H,Liyanarachchi S, Larin A, Savchenko V, Francis GL, de la Chapelle A, et al: Gene expression and functional evidence of epithelial-to-mesenchymal transition in papillary thyroid carcinoma invasion. Proc Natl Acad Sci USA 104: 2803-2808, 2007.

8. Karakas B, Bachman KE and Park BH: Mutation of the PIK3CA oncogene in human cancers. Br J Cancer 94: 455-459, 2006.

9. Liu D, Hou P, Liu Z, Wu G and Xing M: Genetic alterations in the phosphoinositide 3-kinase/Akt signaling pathway confer sensitivity of thyroid cancer cells to therapeutic targeting of Akt and mammalian target of rapamycin. Cancer Res 69: 7311-7319, 2009.

10. Wojciechowska-Durczyńska K, Krawczyk-Rusiecka K, Cyniak-Magierska A, Zygmunt A, Gałecka E and Lewiński A: Relative quantification of PIK3CA gene expression level in fine-needle aspiration biopsy thyroid specimens collected from patients with papillary thyroid carcinoma and non-toxic goitre by real-time RT-PCR. Thyroid Res 3: 5, 2010.

11. Masago K, Asato R, Fujita S, Hirano S, Tamura Y, Kanda T, Mio T, Katakami N, Mishima M and Ito J: Epidermal growth factor receptor gene mutations in papillary thyroid carcinoma. Int J Cancer 124: 2744-2749, 2009.

12. Cha YJ and Koo JS: Next-generation sequencing in thyroid cancer. J Transl Med 14: 322, 2016.

13. Tuttle RM, Haugen B and Perrier ND: Updated American joint committee on cancer/tumor-node-metastasis staging system for differentiated and anaplastic thyroid cancer (Eighth Edition) What changed and why? Thyroid 27: 751-756, 2017.

14. Volante M, Collini P, Nikiforov YE, Sakamoto A Kakudo K, Katoh R, Lloyd RV, LiVolsi VA, Papotti M, Sobrinho-Simoes M, et al: Poorly differentiated thyroid carcinoma: The Turin proposal for the use of uniform diagnostic criteria and an algorithmic diagnostic approach. Am J Surg Pathol 31: 1256-1264, 2007.

15. Ellison G, Huang S, Carr H, Wallace A, Ahdesmaki M, Bhaskar S and Mills J: A reliable method for the detection of BRCA1 and BRCA2 mutations in fixed tumour tissue utilising multiplex PCR-based targeted next generation sequencing. BMC Clin Pathol 15: 5, 2015

16. Gremel G, Lee RJ, Girotti MR, Mandal AK, Valpione S Garner G, Ayub M, Wood S, Rothwell DG, Fusi A, et al: Distinct subclonal tumour responses to therapy revealed by circulating cell-free DNA. Ann Oncol 27: 1959-1965, 2016.

17. Kimura ET, Nikiforova MN, Zhu Z, Knauf JA, Nikiforov YE and Fagin JA: High prevalence of BRAF mutations in thyroid cancer: Genetic evidence for constitutive activation of the RET/PTC-RAS-BRAF signaling pathway in papillary thyroid carcinoma. Cancer Res 63: 1454-1457, 2003.

18. Namba H, Nakashima M, Hayashi T, Hayashida N, Maeda S Rogounovitch TI, Ohtsuru A, Saenko VA, Kanematsu T and Yamashita S: Clinical implication of hot spot BRAF mutation, V599E, in papillary thyroid cancers. J Clin Endocrinol Metab 88: 4393-4397, 2003

19. Şahpaz A, Önal B, Yeşilyurt A, Han Ü and Delibaşı T: BRAF (V600E) mutation, RET/PTC1 and PAX8-PPAR gamma rearrangements in follicular epithelium derived thyroid lesions-institutional experience and literature review. Balkan Med J 32: 156-166, 2015.

20. Fernandez IJ, Piccin O, Sciascia S, Cavicchi O, Repaci A Vicennati V and Fiorentino M: Clinical significance of BRAF mutation in thyroid papillary cancer. Otolaryngol Head Neck Surg 148: 919-925, 2013.

21. Li C, Aragon Han P, Lee KC, Lee LC, Fox AC, Beninato T, Thiess M, Dy BM, Sebo TJ, Thompson GB, et al: Does BRAF V600E mutation predict aggressive features in papillary thyroid cancer? Results from four endocrine surgery centers. J Clin Endocrinol Metab 98: 3702-3712, 2013.

22. Kim TH, Park YJ, Lim JA, Ahn HY, Lee EK, Lee YJ, Kim KW, Hahn SK, Youn YK, Kim KH, et al: The association of the BRAF (V600E) mutation with prognostic factors and poor clinical outcome in papillary thyroid cancer: A meta-analysis. Cancer 118: 1764-1773, 2012

23. Xing M, Alzahrani AS, Carson KA, Shong YK, Kim TY, Viola D, Elisei R, Bendlová B, Yip L, Mian C, et al: Association between BRAF V600E mutation and recurrence of papillary thyroid cancer. J Clin Oncol 33: 42-50, 2015.

24. Liang J, Cai W, Feng D, Teng H, Mao F, Jiang Y, Hu S, Li X, Zhang Y, Liu B and Sun ZS: Genetic landscape of papillary thyroid carcinoma in the Chinese population. J Pathol 244: 215-226, 2018
25. Yim JH, Kim WG, Jeon MJ, Han JM, Kim TY, Yoon JH, Hong SJ, Song DE, Gong G, Shong YK and Kim WB: Association between expression of $\mathrm{X}$-linked inhibitor of apoptosis protein and the clinical outcome in a BRAF V600E-prevalent papillary thyroid cancer population. Thyroid 24: 689-694, 2014.

26. Lee MY, Ku BM, Kim HS, Lee JY, Lim SH, Sun JM, Lee SH, Park K, Oh YL, Hong M, et al: Genetic alterations and their clinical implications in high-recurrence risk papillary thyroid cancer. Cancer Res Treat 49: 906-914, 2017.

27. Kim WW, Ha TK and Bae SK: Clinical implications of the BRAF mutation in papillary thyroid carcinoma and chronic lymphocytic thyroiditis. J Otolaryngol Head Neck Surg 47: 4, 2018.

28. Kim HJ, Park HK, Byun DW, Suh K, Yoo MH, Min YK, Kim SW and Chung JH: Iodine intake as a risk factor for BRAF mutations in papillary thyroid cancer patients from an iodine-replete area. Eur J Nutr 57: 809-815, 2018.

29. Guan H, Ji M, Bao R, Yu H, Wang Y, Hou P, Zhang Y, Shan Z, Teng $\mathrm{W}$ and Xing $\mathrm{M}$ : Association of high iodine intake with the T1799A BRAF mutation in papillary thyroid cancer. J Clin Endocrinol Metab 94: 1612-1617, 2009.

30. Elisei R, Viola D, Torregrossa L, Giannini R, Romei C, Ugolini C, Molinaro E, Agate L, Biagini A, Lupi C, et al: The BRAF(V600E) mutation is an independent, poor prognostic factor for the outcome of patients with low-risk intrathyroid papillary thyroid carcinoma: Single-institution results from a large cohort study. J Clin Endocrinol Metab 97: 4390-4398, 2012.

31. Vuong HG, Altibi AM, Abdelhamid AH, Ngoc PU, Quan VD, Tantawi MY, Elfil M, Vu TL, Elgebaly A, Oishi N, et al: The changing characteristics and molecular profiles of papillary thyroid carcinoma over time: A systematic review. Oncotarget 8 : 10637-10649, 2017.

32. Jin L, Chen E, Dong S, Cai Y, Zhang X, Zhou Y, Zeng R, Yang F, Pan C, Liu Y, et al: BRAF and TERT promoter mutations in the aggressiveness of papillary thyroid carcinoma: A study of 653 patients. Oncotarget 7: 18346-18355, 2015.

33. Nakayama H, Yoshida A, Nakamura Y, Hayashi H, Miyagi Y, Wada N, Rino Y, Masuda M and Imada T: Clinical significance of BRAF (V600E) mutation and Ki-67 labeling index in papillary thyroid carcinomas. Anticancer Res 27: 3645-3649, 2007.

34. Barbaro D, Incensati RM, Materazzi G, Boni G, Grosso M, Panicucci E, Lapi P, Pasquini C and Miccoli P: The BRAF V600E mutation in papillary thyroid cancer with positive or suspected pre-surgical cytological finding is not associated with advanced stages or worse prognosis. Endocrine 45: 462-468, 2014.

35. Nikiforova MN, Wald AI, Roy S, Durso MB and Nikiforov YE: Targeted next-generation sequencing panel (ThyroSeq) for detection of mutations in thyroid cancer. J Clin Endocrinol Metab 98: E1852-E1860, 2013.

36. Goldenberg D, Russo M, Houser K, Crist H, Derr JB, Walter V, Warrick JI, Sheldon KE, Broach J and Bann DV: Altered molecular profile in thyroid cancers from patients affected by the three mile island nuclear accident. Laryngoscope 127 (Suppl 3): S1-S9, 2017.

37. Landa I, Ibrahimpasic T, Boucai L, Sinha R, Knauf JA, Shah RH, Dogan S, Ricarte-Filho JC, Krishnamoorthy GP, Xu B, et al: Genomic and transcriptomic hallmarks of poorly differentiated and anaplastic thyroid cancers. J Clin Invest 126: 1052-1066, 2016.

38. Sims D, Sudbery I, Ilott NE, Heger A and Ponting CP: Sequencing depth and coverage: Key considerations in genomic analyses. Nat Rev Genet 15: 121-132, 2014.

39. Walsh T, Lee MK, Casadei S, Thornton AM, Stray SM, Pennil C, Nord AS, Mandell JB, Swisher EM and King MC: Detection of inherited mutations for breast and ovarian cancer using genomic capture and massively parallel sequencing. Proc Natl Acad Sci USA 107: 12629-12633, 2010

40. Lin MT, Mosier SL, Thiess M, Beierl KF, Debeljak M, Tseng LH, Chen G, Yegnasubramanian S, Ho H, Cope L, et al: Clinical validation of KRAS, BRAF, and EGFR mutation detection using next-generation sequencing. Am J Clin Pathol 141: 856-866, 2014.

41. Lim JY, Hong SW, Lee YS, Kim BW, Park CS, Chang HS and Cho JY: Clinicopathologic implications of the BRAF(V600E) mutation in papillary thyroid cancer: A subgroup analysis of 3130 cases in a single center. Thyroid 23: 1423-1430, 2013.

42. Chen Y, Sadow PM, Suh H, Lee KE, Choi JY, Suh YJ, Wang TS and Lubitz CC: BRAF(V600E) is correlated with recurrence of papillary thyroid microcarcinoma: A systematic review, multi-institutional primary data analysis, and meta-analysis. Thyroid 26: 248-255, 2016 
43. Xing M,Alzahrani AS, Carson KA, Viola D, Elisei R, Bendlova B, Yip L, Mian C, Vianello F, Tuttle RM, et al: Association between BRAF V600E mutation and mortality in patients with papillary thyroid cancer. JAMA 309: 1493-1501, 2013.

44. Kim TY, Kim WB, Song JY, Rhee YS, Gong G, Cho YM, Kim SY, Kim SC, Hong SJ and Shong YK: The BRAF mutation is not associated with poor prognostic factors in Korean patients with conventional papillary thyroid microcarcinoma. Clin Endocrinol (Oxf) 63: 588-593, 2005

45. Nikiforov YE: Radiation-induced thyroid cancer: What we have learned from chernobyl. Endocr Pathol 17: 307-317, 2006.

46. Ito $Y$, Yoshida H, Kihara M, Kobayashi K, Miya A and Miyauchi A: BRAF(V600E) mutation analysis in papillary thyroid carcinoma: Is it useful for all patients? World J Surg 38: 679-687, 2014

47. Pelttari H, Schalin-Jäntti C, Arola J, Löyttyniemi E, Knuutila S and Välimäki MJ: BRAF V600E mutation does not predict recurrence after long-term follow-up in TNM stage I or II papillary thyroid carcinoma patients. APMIS 120: 380-386, 2012.

48. Shimamura M, Nakahara M, Orim F, Kurashige T, Mitsutake N, Nakashima M, Kondo S, Yamada M, Taguchi R, Kimura S and Nagayama Y: Postnatal expression of BRAFV600E does not induce thyroid cancer in mouse models of thyroid papillary carcinoma. Endocrinology 154: 4423-4430, 2013.

49. Watanabe R, Hayashi Y, Sassa M, Kikumori T, Imai T, Kiuchi T and Murata Y: Possible involvement of BRAFV600E in altered gene expression in papillary thyroid cancer. Endocr J 56: 407-414, 2009.

50. Mesa C Jr, Mirza M, Mitsutake N, Sartor M, Medvedovic M Tomlinson C, Knauf JA, Weber GF and Fagin JA: Conditional activation of RET/PTC3 and BRAFV600E in thyroid cells is associated with gene expression profiles that predict a preferential role of BRAF in extracellular matrix remodeling. Cancer Res 66 6521-6529, 2006.

51. Palona I, Namba H, Mitsutake N, Starenki D, Podtcheko A, Sedliarou I, Ohtsuru A, Saenko V, Nagayama Y, Umezawa K and Yamashita S: BRAFV600E promotes invasiveness of thyroid cancer cells through nuclear factor kappaB activation. Endocrinology 147: 5699-5707, 2006

52. Franzoni A, Dima M, D'Agostino M, Puppin C, Fabbro D Loreto CD, Pandolfi M, Puxeddu E, Moretti S, Celano M, et al: Prohibitin is overexpressed in papillary thyroid carcinomas bearing the BRAF(V600E) mutation. Thyroid 19: 247-255, 2009 .
53. Jo YS, Li S, Song JH, Kwon KH, Lee JC, Rha SY, Lee HJ, Sul JY, Kweon GR, Ro HK, et al: Influence of the BRAF V600E mutation on expression of vascular endothelial growth factor in papillary thyroid cancer. J Clin Endocrinol Metab 91: 3667-3670, 2006.

54. Giordano TJ, Kuick R, Thomas DG, Misek DE, Vinco M, Sanders D, Zhu Z, Ciampi R, Roh M, Shedden K, et al: Molecular classification of papillary thyroid carcinoma: Distinct BRAF, RAS, and RET/PTC mutation-specific gene expression profiles discovered by DNA microarray analysis. Oncogene 24: 6646-6656, 2005.

55. Oishi N, Kondo T, Ebina A, Sato Y, Akaishi J, Hino R, Yamamoto N, Mochizuki K, Nakazawa T, Yokomichi H, et al: Molecular alterations of coexisting thyroid papillary carcinoma and anaplastic carcinoma: Identification of TERT mutation as an independent risk factor for transformation. Mod Pathol 30: 1527-1537, 2017.

56. Penna GC, Vaisman F, Vaisman M, Sobrinho-Simões M and Soares P: Molecular markers involved in tumorigenesis of thyroid carcinoma: Focus on aggressive histotypes. Cytogenet Genome Res 150: 194-207, 2016

57. Jiang L, Chu $\mathrm{H}$ and Zheng $\mathrm{H}$ : B-Raf mutation and papillary thyroid carcinoma patients. Oncol Lett 11: 2699-2705, 2016.

58. Samuels Y and Velculescu VE: Oncogenic mutations of PIK3CA in human cancers. Cell Cycle 3: 1221-1224, 2004.

59. Arsenic R, Treue D, Lehmann A, Hummel M, Dietel M, Denkert C and Budczies J: Comparison of targeted next-generation sequencing and sanger sequencing for the detection of PIK3CA mutations in breast cancer. BMC Clin Pathol 15: 20, 2015.

60. Sharma SV, Bell DW, Settleman J and Haber DA: Epidermal growth factor receptor mutations in lung cancer. Nat Rev Cancer 7: 169-181, 2007.

61. Ciardiello F and Tortora G: EGFR antagonists in cancer treatment. N Engl J Med 358: 1160-1174, 2008.

62. Lee DH, Lee GK, Kong SY, Kook MC, Yang SK, Park SY, Park SH, Keam B, Park DJ, Cho BY, et al: Epidermal growth factor receptor status in anaplastic thyroid carcinoma. J Clin Pathol 60: 881-884, 2007.

63. Nikiforova MN, Mercurio S, Wald AI, Barbi de Moura M, Callenberg K, Santana-Santos L, Gooding WE, Yip L, Ferris RL and Nikiforov YE: Analytical performance of the ThyroSeq v3 genomic classifier for cancer diagnosis in thyroid nodules. Cancer 124: 1682-1690, 2018. 